\title{
An eye ultrastructure investigation of a plant pest Acyrthosiphon pisum (Harris) (Insecta: Hemiptera: Aphididae)
}

\section{Monalisa Mishra}

Department of Life Science, National Institute of Technology (NIT)

Rourkela, Rourkela, Orissa, India
Correspondence: Monalisa Mishra Department of Life Science, NIT Rourkela, Rourkela, Orissa 769008, India Email mishramo@nitrkl.ac.in
This article was published in the following Dove Press journal:

Open Access Insect Physiology

16 December 2015

Number of times this article has been viewed

\begin{abstract}
The pea aphid Acyrthosiphon pisum (Harris) possess two compound eyes on either side of the head like most other insects. The compound eyes were examined under light and electron microscope to reveal the final structural arrangement. Each eye contains approximately two hundred well separated circular functional units called ommatidia. Each ommatidium has a cornea and eucone type of cone with eight retinula cells, which give rise to a closed rhabdom. The cornea together with the cone form the dioptric apparatus of the ommatidium. The dioptric apparatus focuses the light to the rhabdom which is the light sensing organelle of the eye. There is no space between the distal part of the rhabdom and the cone. The distal rhabdom appears circular in tranverse section. Each rhabdom contains many finger-like projections called microvilli that are packed with the visual pigment opsin. The microvilli are arranged in four different compartments distally. Proximally, the microvilli are arranged in three different directions making an angle of $120^{\circ}$ with each other. The arrangement of the cells in the eye shows that it has an apposition type of eye with closed rhabdom pattern.
\end{abstract}

Keywords: aphid vision, apposition eye, photoreceptor, closed rhabdom, primary pigment granule, secondary pigment granule

\section{Introduction}

Aphids are small sap-sucking insects belonging to the superfamily Aphidoidea ${ }^{1}$ and order Hemiptera. Aphids are often referred to as plant lice, greenflies, blackflies, or whiteflies. The size of the aphid varies from 1 to $10 \mathrm{~mm}$. Out of $\sim 4,400$ known species, around 250 species are pests of agriculture and forestry. ${ }^{2,3}$ They can migrate great distances through passive dispersal in winds. Besides wind, aphids can be spread by human transportation of infested plant materials. The vision of the insect plays a crucial role in detecting the host species for transportation. ${ }^{4}$ The visibility of an entity depends on the 1) size of the entity, 2) distance between the size of the entity and eye, and 3 ) visual acuity of the eye. In addition, morphological and physiological conditions such as size and number of ommatidia also influence target detectability under given light conditions. Pea aphids are economically important insects since they are pests for many crops. Insects use their eyes for finding the food and partner. Thus, any damage to the eye will affect the functionality of the animal. Although the eyes of pea aphid indirectly play an important role in the crop damage, ${ }^{4,5}$ literature describing the ultrastructure of the eye is scarce. An investigation on the ultrastructure of the eye of pea aphid will help the entomologist, horticulturist, and anatomist in various ways. 


\section{Materials and methods}

The eyes of the pea aphid were processed for transmission electron microscopic (TEM) analysis by an already reported protocol. ${ }^{6}$ The heads ( $4 \mathrm{~mm}$ in size) of six adult Acyrthosiphon pisum were dissected under light microscope. Heads were immediately fixed with a cocktail mixture of $2.5 \%$ glutaraldehyde and 2\% paraformaldehyde diluted with phosphate-buffered saline (PBS) and kept overnight at $4{ }^{\circ} \mathrm{C}$. This step is referred to as the primary fixation. On the next day, heads were washed with PBS and were subjected to secondary fixation with $2 \%$ osmium for 1 hour. This step was carried out in darkness at room temperature. Heads were washed with water to remove the osmium stain. Then, heads were subjected to serial ethanol dehydration. Dehydration steps were performed with $50 \%, 70 \%, 90 \%, 2 \times 100 \%$ ethanol, and $2 \times$ propylene oxide for 10 minutes. Dehydration step was followed by the infiltration with resin. First, the heads were transferred to a mixture containing 1:1 ratio of resin and polypropylene oxide. This step was carried out at room temperature overnight. Next day, the heads were transferred to a mixture containing 3:1 ratio of resin and propylene oxide. Lastly, the heads were transferred to pure resin for 6 hours. Finally, samples were embedded in pure resin and polymerized at $60^{\circ} \mathrm{C}$ overnight.

The resin blocks containing the heads were first trimmed and semi-thin sections of $500 \mathrm{~nm}$ were cut with an ultramicrotome (Leica Ultracut; Leica Microsystems, Wetzlar, Germany). Sections were collected on a glass slide and stained with toluidine blue for contrast enhancement. From appropriate regions, ultrathin sections $(\sim 70 \mathrm{~nm})$ were cut using a diamond knife. Ultrathin sections were collected on a coated grid and stained with $2 \%$ uranyl acetate followed by lead citrate solution for contrast enhancement. Stained grids were stored in a dry place and examined under electron microscope (FEI Tecnai 12 Bio Twin; FEI Europe BV, Eindhoven, Holland, the Netherlands). Grids were imaged digitally (Morada digital camera SiS), and all images were processed using Adobe Photoshop.

\section{Results}

\section{General features of compound eye}

Six heads of adult $A$. pisum were used for this study. Two compound eyes were present behind the antennae on the dorsal side of the head. Each eye is circular in outline, and no differences between left and right eye were noticed. The facets are more or less circular in shape and their diameters vary from 8 to $10 \mu \mathrm{m}$ in size. Neighboring facets are well separated from each other by undifferentiated, interfacetal cuticle (Figure 1). Interommatidial hair, reported from other insect species, was absent in A. pisum. Each facet or ommatidium is composed of a corneal lens, four cone cells, and eight photoreceptive cells (retinula cells), which form the rhabdom (Figure 2). Each ommatidium also contains various pigment cells, such as primary, interommatidial, and secondary pigment cells. The secondary pigment cells are abundantly found right above and below the basal lamina. All the eight retinula cells pass through the basal lamina and form axon.

\section{Dioptric structures Cornea}

The cornea is biconvex in structure. The outer radius of curvature is $\sim 7.5 \mu \mathrm{m}$ in a sectioned eye (Figure 3 ). The thickness of the cornea at the central part varies from 2.3 to $2.5 \mu \mathrm{m}$. At the marginal region, the thickness of the cornea is $1.7 \mu \mathrm{m}$. The cornea has many repeated units at a distance of $~ 0.2 \mu \mathrm{m}$ at the proximal level (Figure 3, marked in white bracket). At the distal level the lamination is compact, and it is difficult to measure the length of the individual chitinous layers (Figure 3).

\section{Cone and pigment cells}

There are four cone cells immediately below the cornea. The nuclei of the cone cells are found at the distal-most part of the cone cells (Figure 3). The nucleus is $4.5 \mu \mathrm{m}$ in length and appears as a bean-shaped structure (Figure 3).

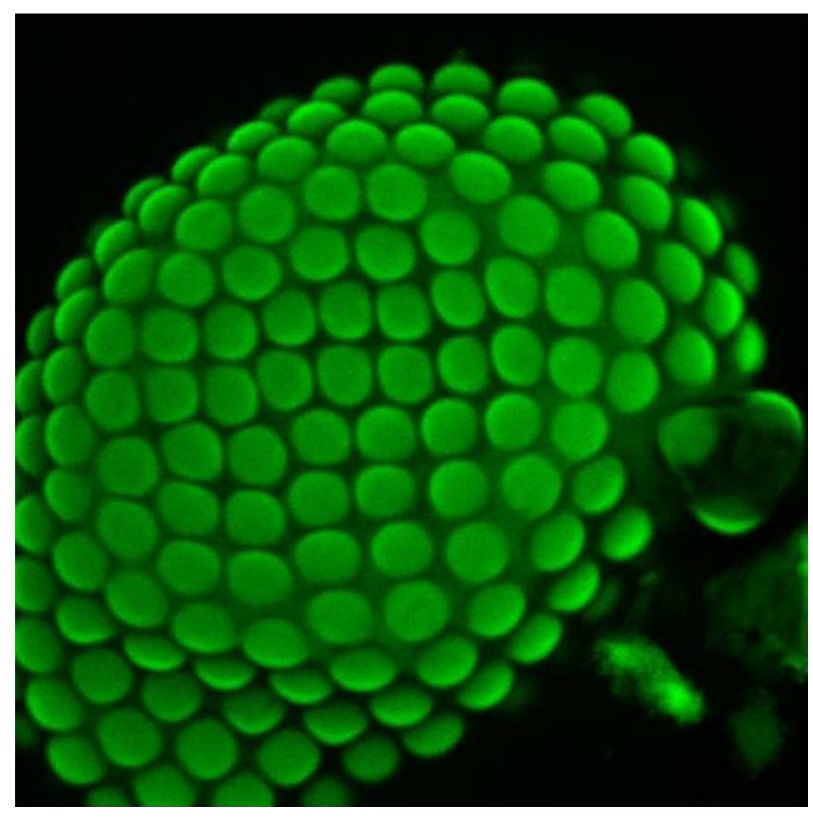

Figure I A confocal image of the eye (stained with phalloidin conjugated with Alexa 488) of Acyrthosiphon pisum depicting the loose arrangement of facets/ ommatidia in the eye. 


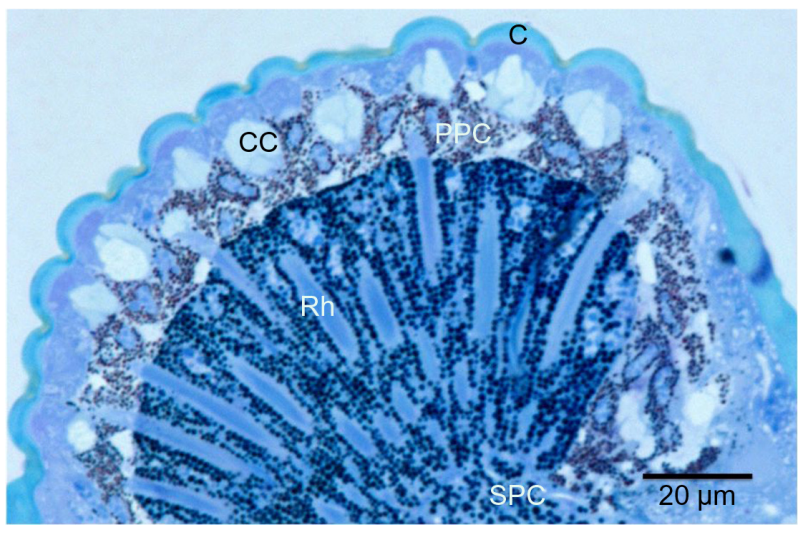

Figure 2 Light micrograph of longitudinally sectioned (LS) light-adapted eye of Acyrthosiphon pisum fixed during the daytime.

Notes: Each ommatidium depicts the presence of cornea $(C)$ as a convex outward projection beneath which is a crystalline cone (CC) followed by rhabdom (Rh). At the level of cone the primary pigment cells (PPC) are present and at the level of rhabdom secondary pigment cells (SPC) are found. Note the difference in size between the primary and secondary pigment granules.

The nucleus has dark karyoplasm which gives rise to a composite crystalline material having similarity with eucone type of cone. ${ }^{7}$ There exists some cytoplasmic variation from distal to proximal part of the cone. In a transverse section, cone cells appear circular in outline and each cone is formed of four cells (Figure 4A), which combine to make up a cone that is $4.5 \mu \mathrm{m}$ long. The distal-most part measures $2.8 \mu \mathrm{m}$ in diameter and the proximal part measures $0.6 \mu \mathrm{m}$ (Figures 2, $4 \mathrm{~B}$ and $\left.\mathrm{B}^{\prime}\right)$. Very few organelles are found in the cone cells,

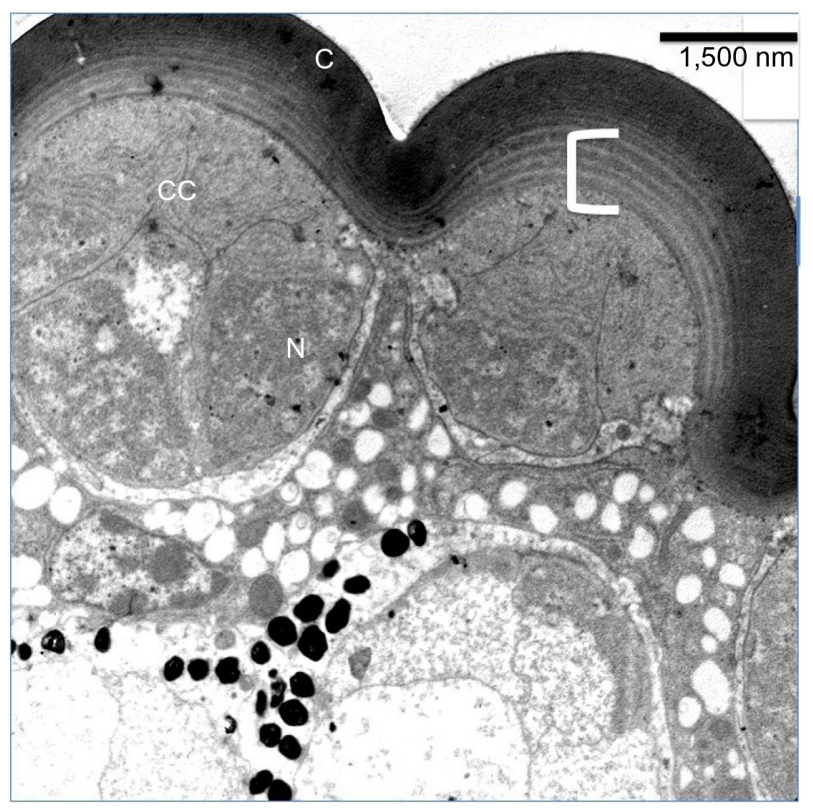

Figure 3 Transmission electron micrograph of sections through the dioptric apparatus of the eye of Acyrthosiphon pisum.

Notes: Oblique section showing part of the cornea (C) and cone (CC). Nuclei (N) of the cone cells are observed below the cornea. Layering of the cornea is more prominent at the proximal part, and multiple layerings are marked with white bracket. which include microtubules, microfilaments, and cisternae of rough endoplasmic reticulum. At the level of rhabdom, the cone cell splits (Figure 5) and runs as "cone cell root" between the retinula cells (Figure 6). Proximal part of the cone is in continuation with the distal part of the photoreceptive cell or rhabdom (Figure 5). Just above the basement membrane, roots of the cone cell enlarge and reunite to form a cap for rhabdom.

\section{Primary and secondary pigment cells}

There are two primary pigment cells in each ommatidium. The primary pigment cells are directly in contact with the proximal part of the cornea. The primary pigment cells form a sleeve around the distal part of the cone. The cornea and corneogenous cells adhere together by means of adherens junctions. Surrounding the primary pigment cell, numerous secondary pigment cells are found. The diameter of the pigment granules of the primary pigment cells measures from 0.4 to $0.8 \mu \mathrm{m}$ (Figures 2 and 5). The pigment granules are irregular in shape (Figure 5). The difference between the shape of the primary and secondary pigment granules can be easily differentiated in a longitudinal section (Figures 2 and 5). The secondary pigment granules vary from 0.5 to $0.7 \mu \mathrm{m}$ in diameter and are spherical in shape. The secondary pigment cells have their nuclei at the distal-most region of the eye. The nuclei size of the secondary pigment cells are smaller than the primary pigment cells. The secondary pigment cells extend to the basement membrane.

\section{Retinula cells and rhabdoms}

Transverse section through the transition zone of the cone and the rhabdom illustrates the presence of seven retinula cells (Figure 6). In between the retinula cells, four cone cell processes are found. Cone cell processes are identified by the presence of electron-dense material in them. Thus, cone cell processes are used as a marker while labeling the retinula cell (Figure 6). At the distal level, the diameter of the rhabdom is $1.5-2 \mu \mathrm{m}$. The microvilli are regular in shape and their diameter range is from 40 to $45 \mathrm{~nm}$. Microvilli from neighboring retinula cell is orthogonal to each other. At the level of rhabdom, adherent junctions and cone tract are found. The nuclei of the retinula cells are found at different levels of the rhabdom. At the very distal part of the rhabdom, that is, when it meets the cone cells, four nuclei are found, and proximal to this three more nuclei are found. The nuclei of the eighth retinular cell appears close to the basement membrane. Although the nuclei appear at different levels, their shape and structure remain the same throughout the retina (Figures 6 and 7). The arrangement of the 


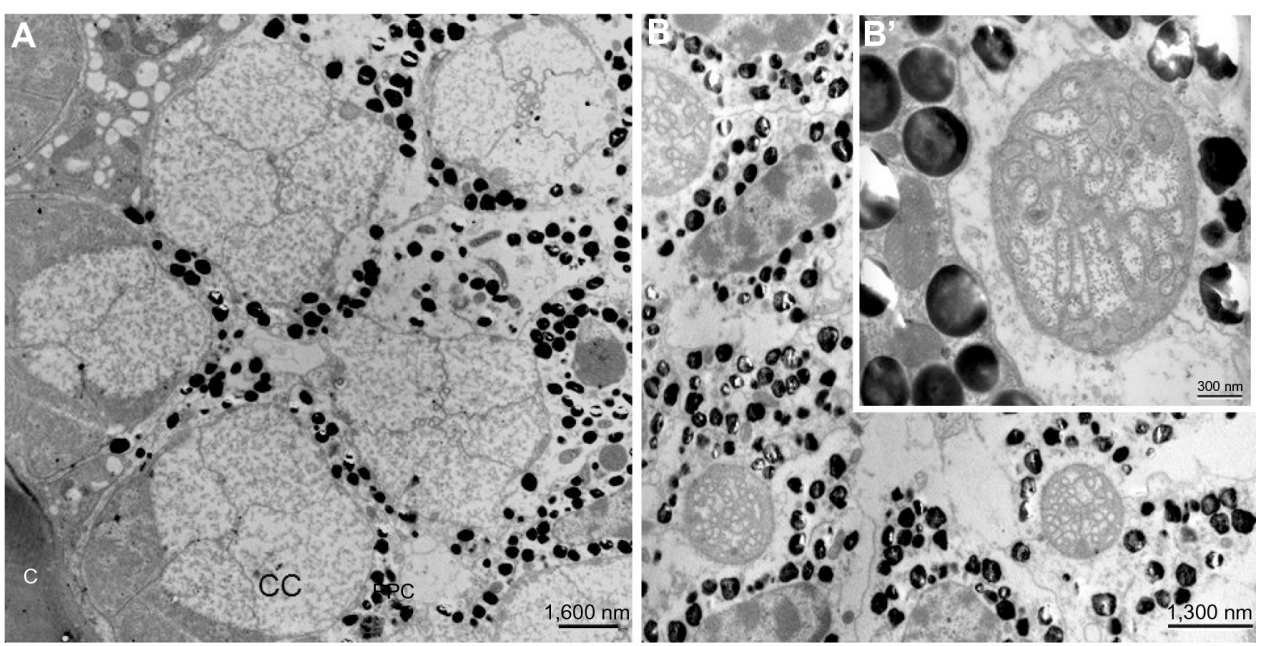

Figure 4 Transmission electron micrograph of sections through the cone of the eye of Acyrthosiphon Pisum.

Notes: (A) Transverse section through the eye showing cornea (C), unequal contribution of cone cells (CC) surrounded by the nuclei of the primary pigment cells (PPC). (B) Proximal region of the cone is surrounded by primary and secondary pigment cells with their granules. (B') Higher magnification of the proximal region of the cone.

rhabdomere varies at both distal and proximal levels. Distally, the rhabdom is divided into four different quadrants and the microvilli are arranged in four different directions. Proximally, the rhabdomere of each retinula cell is arranged in three directions making an angle of $120^{\circ}$ to each other. Just above the basement membrane, all the eight retinula cells reunite to form the axon and pass through the basal lamina. Underneath the basal lamina, nuclei of interommatidial pigment cells and

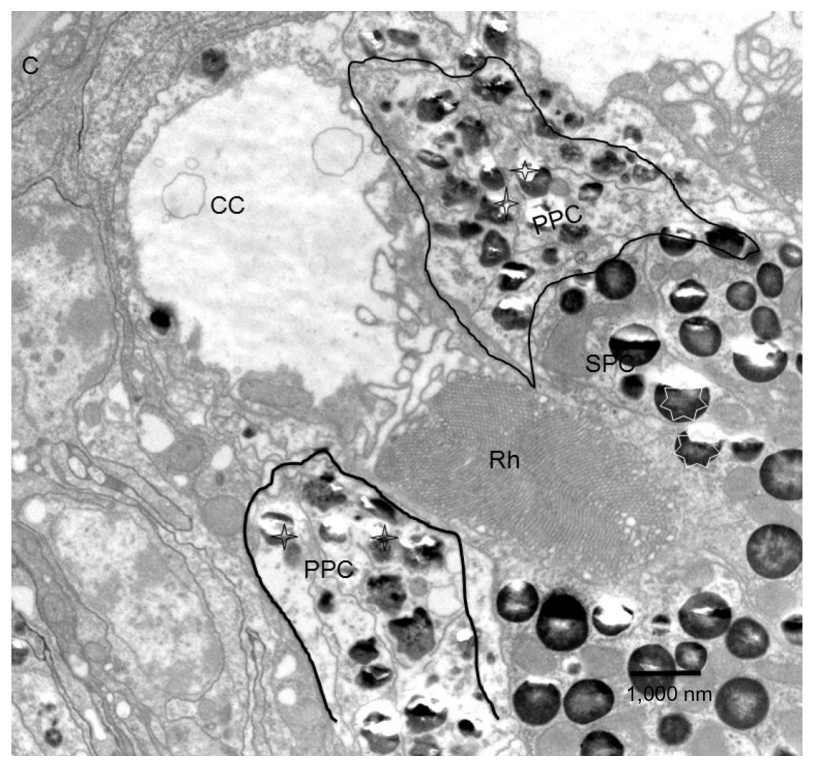

Figure 5 Transmission electron micrograph of the longitudinal section through cornea (C) and cone (CC).

Notes: Distally, the cone cells are in contact with the $C$ and proximally with the rhabdom (Rh). One of the two primary pigment cells (PPC) with its numerous microtubules is seen next to the cone cell. Primary pigment cells are characterized by their irregular pigment granules. Note the difference in the arrangement of the pigment granules of primary (PPC maker as four star) and secondary pigment cells (SPC marked as seven star). some electron-dense pigment granules are present. In the retinular cells, various organelles like mitochondria, ribosome, endoplasmic reticulum, and golgi apparatus are found. Some electron-opaque pigment granules of diameter $0.5-0.7 \mu \mathrm{m}$ are also found in the ommatidium.

\section{Discussion}

Morphologically, the eye of A. pisum is an apposition type of eye as described by Exner. ${ }^{8}$ Apposition eyes are widely found in insects that are active during the daytime rather than at

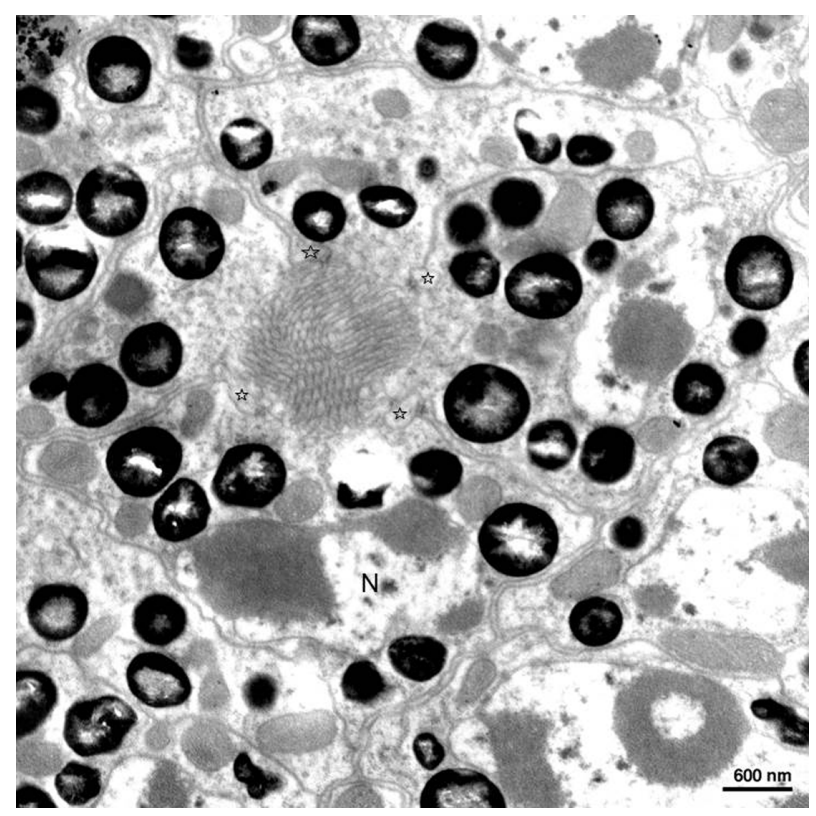

Figure 6 Transmission electron micrograph of the transverse section through the distal rhabdom depicting nuclei $(\mathrm{N})$ of the retinular cells and cone tract (pointed by stars). 


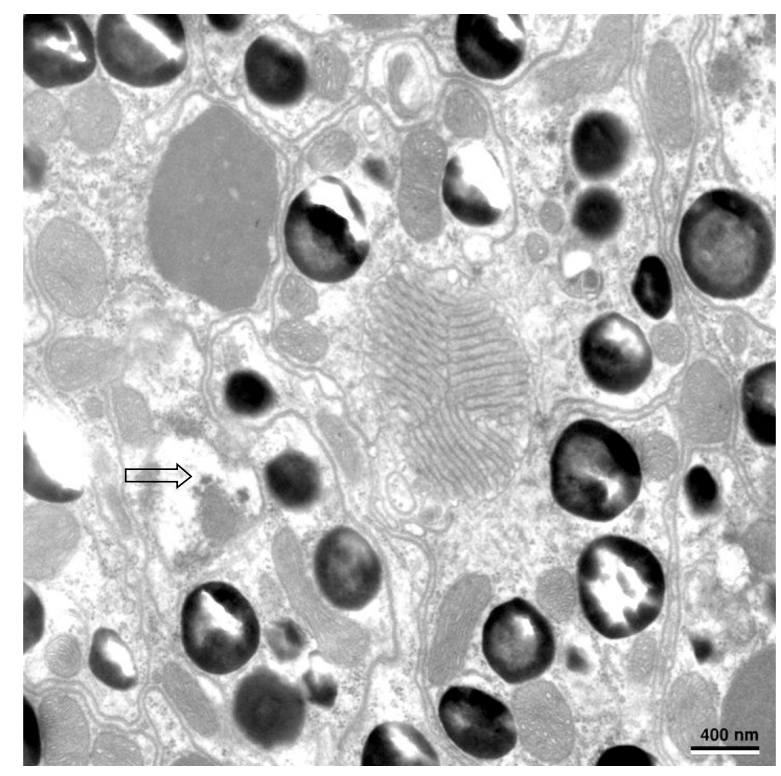

Figure 7 The nuclei of the proximal retinular cells (marked with arrow) and the triangular arrangement of rhabdomere of retinula cell.

night. ${ }^{9}$ Furthermore, insects having small body length (shorter than $4 \mathrm{~mm}$ ) retain such type of eyes irrespective of their time of activity. ${ }^{10}$ Most Hemiptera have apposition type of eye, although variations are observed in the ultrastructure of the eye depending on the habitat and time of the activity of the animal. ${ }^{11-13}$ Nocturnal Hemiptera like Triatoma infestans has apposition type of eye with certain modifications. ${ }^{14}$ Similar modification is also observed in nocturnal helictid bee Megalopta genalis. ${ }^{15}$ In both T. infestans and M. genalis, the apposition eye undergoes several structural modifications to cope with the dark environment, which include massive increase in the size of dioptric and photoreceptive apparatus to capture more light. ${ }^{16,17}$

The facets of $A$. pisum are loosely arranged and circular in shape. Loose arrangement of facets suggests poor vision in A. pisum.${ }^{18}$ Compared with other aphid species ${ }^{19}$ A. pisum possesses relatively small ommatidial diameter. ${ }^{19}$ However, the facet diameter satisfies the minimum functional size of lenses as reported by Barlow..$^{20}$ Large facet helps in capturing more light and forming clearer image for the animal, whereas small facet results in lower resolution, as observed in A. pisum. The interommatidial angle in A. pisum is large, ${ }^{21}$ which further suggests that the resolution of the eye must be poor in this organism. Behavioral studies further depict that the pea aphid moves slowly, in the absence of predator. This behaviour is in further agreement with poor resolution observed in the eye of pea aphid. ${ }^{22}$

The cornea is thin and laminated as reported from other Hemiptera species. Thicker cornea helps to attenuate the light intensity and protect the photoreceptors from damage. ${ }^{23}$ Eucone type of cone is present in A. pisum, which helps to capture light in a better manner than the acone type of eye. However, the acone type of eye has better ability to undergo light-dependent changes. ${ }^{10}$ Interommatidial hair reported from other insect species are absent in A. pisum. Absence of interommatidial hair suggests that the eye does not, probably, need a cleaning and protective apparatus to protect from strong light. ${ }^{24,25}$ Numerous secondary pigments are present in the eye, and they are close to the rhabdom in the light-adapted eye. The secondary pigments act as a photon quencher and are thus known to protect the eye from light damage. ${ }^{18,24,25}$

Rhabdom, the photoreceptor organ, is formed of eight photoreceptor cells that fuse to form a closed rhabdom. Closed rhabdom is mostly found in diurnal animals with tight apposition between cone and rhabdom. A sheath of secondary pigments surround the rhabdom of apposition type of eye. During light adaptation, pigments migrate close to the rhabdom and thus help to protect the rhabdom from photic stress. ${ }^{18}$ In A. pisum, it is observed that the pigments do not migrate very close to the rhabdom, suggesting that the rhabdom might be under photic stress. The damage to microvilli resulting from photic stress, as reported in Prothalotia ramburi, ${ }^{18}$ was not observed in A. pisum.

The arrangement of the cells in the distal rhabdom varies from that of the proximal rhabdom. In the distal rhabdom, the microvilli are arranged orthogonally and proximally the microvilli make an angle of $120^{\circ}$ to each another. Such type of arrangement has been reported from honey bee and cockroach. ${ }^{26}$ The orthogonal arrangement of microvilli at the distal rhabdom helps in making the eye sensitive toward polarized light. ${ }^{27}$ The arrangement of microvilli in the proximal part of the rhabdom helps the insect to detect the e-vector, a component of light that interacts with the microvilli and thus helps to visualize things. ${ }^{28,29}$ Alongwith the arrangement of microvilli within the photoreceptor with various spectral sensitivity is required to detect the various polarization sensitivity in different duration of the day. Green and ultraviolet receptors are reported from aphid eyes. ${ }^{30,31}$ The arrangement of microvilli in the rhabdom as well as the visual pigments suggests that the insect might be sensitive toward e-vector. The insect probably uses e-vector to determine host plants while migrating from one host plant to the other. Further behavioral study on A. pisum will answer more questions about the functioning of the eye.

\section{Disclosure}

The author reports no conflicts of interest in this work. 


\section{References}

1. Blackman RL, Eastop VF. Aphids on the World's Trees: An Identification and Information. Cambridge, England: University Press;1994.

2. Dixon AFG. Aphid Ecology. London: Chapman and Hall; 1998.

3. Blackman RL, Eastop VF. Aphids on the World's Crops: An Identification and Information Guide. Chichester, UK: Wiley; 2000.

4. Doring TF, Chittka L. Visual ecology of aphids-a critical review on the role of colours in host finding. Arthropod Plant Interact. 2007; 1(1):3-16.

5. Moericke V. Über die Lebensgewohnheiten der gefl ügelten Blattläuse (Aphidina) unter besonderer Berücksichtigung des Verhaltens beim Landen [The habits of the winged aphids (Aphidina) taking into account in particular the behavior of the land]. Z Angew Ent. 1955;37:19-91.

6. Mishra M, Knust E. Analysis of the Drosophila compound eye with light and electron microscopy. Methods Mol Biol. 2013;935:161-182.

7. Grenacher H. Untersuchungen über das Sehorgan der Arthropoden, insbesondere der Spinnen, Insekten und Crustaceen [Studies on the sehorgan of arthropods: in particular the spiders, insecta, and crustacea]. Vandenhoek and Ruprecht, Göttingen; 1879.

8. Exner S. Die Physiologie der facettierten Augen von Krebsen und Insecten [The physiology of the faceted eyes of crabs and insects]. Leipzig-Wien: Franz deuticke; 1891.

9. Warrant EJ, McIntyre PD. Arthropod eye design and the physical limits to spatial resolving power. Progr Neurobiol. 1993;40:413-461.

10. Meyer-Rochow VB, Gál J. Dimensional limits for arthropod eyes with superposition optics. Vision Res. 2004;44:2213-2223.

11. Schwind R. Zonation of the optical environment and zonation in the rhabdom structure within the eye of the backswimmer, Notonecta glauca. CellTissue Res.1983;232:53-63.

12. Settembrini BP. The compound eyes of Triatoma infestans and Rhodnius prolixus (Hemiptera: Reduviidae). J MedEntomol. 1984;21:477-479.

13. Jia Lei-Po, Liang Ai-ping. Fine structure of the compound eye of Callitettix versicolor (Insecta: Hemiptera). Ann Entomol Soc Am. 2015;108(3):316-324.

14. Reisenman CE, Insausti TC, Lazzari CR. Light-induced and circadian changes in compound eye of the haematophagous bug Triatoma infestans (Hemiptera: Reduviidae). J Exp Biol. 2002;205:201-210.

15. Greiner B, Ribi WA, Warrant EJ. Retinal and optical adaptations for nocturnal vision in the halictid bee Megalopta genalis . Cell Tissue Res. 2004;316(3):377-390.

16. Land MF. Compound eye structure: matching eye to environment. In Archer SNEA, editor. Adaptive Mechanisms in the Ecology of Vision. Great Britain: Kluwer Academic Publishers; 1999.
17. Land MF, Gibson G, Horwood ZJ. Fundamental differences in the optical structure of the eyes of nocturnal and diurnal mosquitoes. J Comp Physiol A. 1999;185:91-103.

18. Meyer-Rochow VB, Mishra M. Structure and putative function of dark- and light-adapted as well as UV-exposed eyes of the food store pest Psyllipsocus ramburi Sélys-longchamps (Insecta: Psocoptera: Psyllipsocidae). J Insect Physiol. 2007;53(2):157-169.

19. Doring TF, Spathe J. Measurements of eye size and acuity in aphids (Hemiptera: Aphididae) Entomol Gener. 2009;32(2):77-84.

20. Barlow HB. The size of ommatidia in apposition eyes. $J$ Exp Biol. 1952;29:667.

21. Doring TF, Spaethe J. Measurements of Eye size and Acuity in Aphids (Hemiptera: Aphididae) Entomol. Gener. 2009;32(2):77-84.

22. Roitberg BD, Myers JH, Frazer BD. The influence of predators on the movement of apterous pea aphids between plants. J Anita Ecol. 1979;48: 111-122.

23. Mishra M. Eye ultrastructure investigation of Scaphidium japonum Reitter (Coleoptera: Staphylinidae: Scaphidiidae). J Entmol Zool. 2013;1(2):8-16.

24. Mishra M, Meyer-Rochow VB. Fine structure of the compound eye of fungus beetle Neotriplax lewisi (Coleoptera: Cucujiformia: Erotylidae). Invertebr Biol. 2006;125:265-278.

25. Mishra M, Meyer-RochowVB. Eye ultrastructure in the pollen-feeding beetle, Xanthochroa luteipennis (Coleoptera: Cucujiformia: Oedemeridae). J Electron Microsc (Tokyo). 2006;55(6):289-300.

26. Mishra M, Meyer-Rochow VB. Fine structural description of the compound eye of the Madagascar 'hissing cockroach' Grompha dohrina portentosa (Dictyoptera: Blaberidae). Insect Sci. 2008;15:179-192.

27. Horváth G, Varju D. Polarized Light in Animal Vision (Polarization Patterns in Nature). Berlin: Springer Verlag; 2003.

28. Rossel S, Wehner R, Lindauer M. E-vector orientation in bees. J Comp Physiol. 1978;125:1-12.

29. Rossel S, Wehner R. The bee's map of the e-vector pattern in the sky. Proc Natl Acad Sci. 1982;79:4451-4455.

30. Kirchner SM, Doring TF, Saucke H. Evidence for trichromacy in the green peach aphid, Myzus persicae (Sulz.) (Hemiptera: Aphididae). J Insect Physiol. 2005;51:1255-1260.

31. Doring TF, Kirchner SM, Skorupski P, Hardie, J. Spectral sensitivity of the green photoreceptor of winged pea aphids. Physiol Entomol. 2011; 36(4):392-396.
Open Access Insect Physiology

\section{Publish your work in this journal}

Open Access Insect Physiology is an international, peer-reviewed, open access journal publishing original research, reports, reviews and commentaries on all areas of insect physiology. The manuscript management system is completely online and includes a very quick and fair peer-review system, which is all easy to use.

\section{Dovepress}

Visit http://www.dovepress.com/testimonials.php to read real quotes from published authors. 